\section{Gold Catalysis}

Highlights at

19NAM,

Philadelphia,

22-27 May 2005

The 19th North American Catalysis Society Meeting was attended by over 1000 participants including significant representation from both industry and academia. Of the many oral and poster presentations the following highlighted the potential of gold catalysts for commercial applications (see www.19nam.org) There were over forty papers presented where gold played a significant role, and some of these are summarized here (abstracts can be downloaded from the conference website until December 1, 2005).

\section{New approaches to designing selective oxidation catalysts (Plenary Keynote)}

Graham I Hutchings, Cardiff University, UK. Selective oxidation is of key importance in the synthesis of chemical intermediates. For large tonnage processes, molecular oxygen, often as air, is used with highly selective heterogeneous catalysts such as oxides, phosphates or supported metals. The recent interest in selective oxidation using gold catalysts was highlighted. Examples of potential applications include the preferential oxidation of $\mathrm{CO}$ in hydrogen streams containing moisture and $\mathrm{CO}_{2}$ using gold supported on $\mathrm{Fe}_{2} \mathrm{O}_{3}$, the oxidation of cyclohexane to cyclohexanol and cyclohexanone, the conversion of glycerol to glycerate in the presence of base, the oxidation of benzyl alcohol to benzaldehyde under solvent-free conditions, and the selective oxidation of hydrogen to hydrogen peroxide using gold/palladium catalysts.

\section{An Overview of Gold Catalysed Oxidation Processes (Keynote)}

David T Thompson, Consultant to World Gold Council, UK and Project AuTEK, South Africa. Gold and gold/platinum group metal (Au/PGM) catalysts are active under mild conditions or even at ambient temperature or less and this makes them unique. They will therefore be effective in reducing running costs of chemical plants and increasing the selectivity of the reactions involved where applicable. In pollution control applications such as air cleaning, low lightoff autocatalysts, and purification of the hydrogen streams used for fuel cells they have the characteristics to become the catalysts of choice, especially now that their durability and resistance to poisons is being shown to be better than was anticipated. The mechanisms of these gold catalysed reactions are still uncertain but both oxidized and metallic gold are probably involved, and the details depend on types of reaction and the conditions used. The use of gold in conjunction with platinum group metals (PGMs) is producing useful results, and this is illustrated, for example by the commercial processes used for the production of vinyl acetate from ethene using Au-Pd catalysts.

Current developments in liquid phase heterogeneous and homogeneous catalysis were reviewed. These included the use of supported gold catalysts for the oxidation of glucose to gluconic acid, an important food additive, and the selective oxidation of other sugars. Homogeneous catalysis by gold complexes involves both novel syntheses and/or high turnover numbers. These result in solution and the liquid phase indicate that gold has intrinsic catalytic activity when liganded or metallic as well as when oxidized or promoted by oxides.

\section{Effect of Support on the Activity of Gold Catalysts in CO Oxidation}

Unnikrishnan R Pillai and Sarojini Deevi, Philip Morris Inc, USA. A systematic study of the effect of support on Au catalysts prepared by deposition precipitation for $\mathrm{CO}$ oxidation at low temperatures showed that $\mathrm{Au} / \mathrm{CeO}_{2}, \mathrm{Au} / \mathrm{TiO}_{2}$, and $\mathrm{Au} / \mathrm{Fe}_{2} \mathrm{O}_{3}$ were the most active, with ceria being the best. The effect of ceria was attributed to its low temperature reducibility which facilitates interaction with adsorbed CO molecules; it was also found that gold helps to increase the oxygen storage capacity of the support.

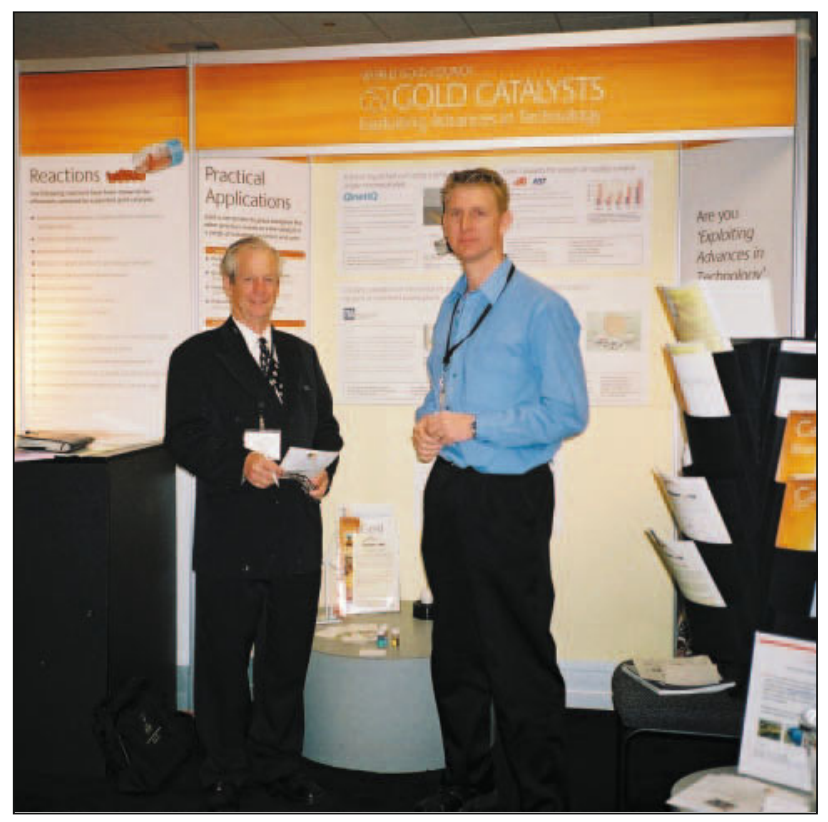


Spectroscopic Evidence of the Supply of Reactive Oxygen during CO Oxidation Catalysed by Gold Supported on Nanocrystalline $\mathrm{CeO}_{2}$

J Guzman, S Carrettin and A Corma, ITQ, Universidad Politecnica de Valencia, Spain. IR spectroscopy showed that $\mathrm{CO}$ adsorption on gold supported on nanocrystalline $\mathrm{CeO}_{2}$ was present as $\mathrm{Au}^{3+}, \mathrm{Au}^{+}$and $\mathrm{Au}^{0}$ as indicated by their characteristic $\mathrm{Au}^{\mathrm{x}} \mathrm{-CO}$ frequencies at 2148, 2130 and 2104 $\mathrm{cm}^{-1}$ respectively. When the $\mathrm{Au} / \mathrm{CeO}_{2}$ catalyst was placed in a flow of oxygen, it was concluded that active catalyst sites incorporate cationic gold.

\section{Supported Gold Complexes and Clusters: Spectroscopic Characterization of Functioning Catalysts for CO Oxidation}

Juan C Fierro-Gonzalez and Bruce C Gates, University of California, Davis, USA. Gold catalyst samples were made from $\mathrm{Au}\left(\mathrm{CH}_{3}\right)_{2}\left(\mathrm{C}_{5} \mathrm{H}_{7} \mathrm{O}_{2}\right)$ and $\mathrm{TiO}_{2}$. The gold was initially present as $\mathrm{Au}^{\prime \prime \prime}$ but heat treatment produced $\mathrm{Au}^{\prime}$ and $\mathrm{Au}^{0}$. The activity of supported gold for $\mathrm{CO}$ oxidation was correlated with the fraction of cationic gold remaining in the sample of catalyst: it was concluded that it should be possible to tune the activities of the catalysts by choice of reaction conditions that maximize the fraction of cationic gold.

\section{Gas-phase Epoxidation of Propylene over Small Gold Ensembles on TS-1}

Bradley Taylor, Lasitha Cumaranatunge, Jochen Lauterbach and W. Nicholas Delgass, Purdue University and University of Delaware, USA. An Au/TS1 system has been shown to produce very active catalysts for the epoxidation of propene on both a per gram of catalyst and a per gram of gold basis. A catalyst with $0.05 w t \%$ Au and Si/Ti ratio of 36 produced $116 \mathrm{~g}_{\mathrm{po}} / \mathrm{hr} / \mathrm{kg}_{\mathrm{cat}}$ at $200^{\circ} \mathrm{C}$ whilst another with $\mathrm{Si} / \mathrm{Ti}=500$ and $0.01 \mathrm{wt} \%$ produced $350 \mathrm{~g}_{\mathrm{po}} / \mathrm{hr} / \mathrm{kg}_{\mathrm{cat}}$ at $200^{\circ} \mathrm{C}$. The increase in $\mathrm{PO}$ rate per gram Au with deceasing gold loading shows an increasingly efficient use of gold to produce the electrophilic oxidant necessary for propene epoxidation. The low gold loadings of these catalysts in combination with the lack of observable gold particles via TEM imply significant activity from entities much smaller than $2 \mathrm{~nm}$.

\section{Remarkable Hydrodechlorination Activity over Silica-Supported Au/Ni Catalysts}

Guang Yuan, Javier Llanos Lopez, Catherine Louis, Laurent Delannoy and Mark A. Keane, University of Kentucky, USA and Université Pierre et Marie Curie, France. The addition of Au to $\mathrm{Ni} / \mathrm{SiO}_{2}$ dramatically improves the hydrodechlorination activity of this catalyst and this represents a significant step forward in the development of efficient catalysis for the low energy non-destructive treatment of toxic haloarenes, eg 2,4-dichlorophenol.

\section{Nanoparticles of Gold on Graphite Produced by dc Magnetron Sputtering and the Oxidation of Glycerol}

Gabriel M Veith, Alberto Villa, Laura Prati, Andrew R Lupini, Stephen J Pennycook and Nancy J Dudney, Oak Ridge National Laboratory, USA and Universita di Milano, Italy. A one step magnetron sputtering technique was used to prepare supported gold catalysts, thus avoiding contamination from solvent or precursor molecules on the surface. The process is economical and environmentally friendly since there is no liquid waste and it is adaptable to a wide range of catalyst supports. The technique produces gold nanoparticles with an average diameter of $1.5 \mathrm{~nm}$ (from STEM). XPS results show that gold is $\mathrm{Au}^{0}$. The particles are highly active towards the oxidation of glycerol (99\% conversion in $4 \mathrm{~h}$, 1,000 glycerol:1Au).

\section{$\mathrm{Au} / \mathrm{TiO}_{2}$ Catalyst Prepared by Impregnation Method for Low Temperature Oxidation of $\mathrm{H}_{2}$ and $\mathrm{CO}$}

Venu Arunajatesan, Mathias Viandt, ShaRee McIntosh, Marisa Cruz, Roman Renneke and Baoshu Chen, Degussa Corporation, Kentucky USA and Degussa AG, Hanau, Germany. An impregnation method has been devised for gold catalyst preparation on a commercial scale at reasonable cost. The volume of solvent used is 60 times less than for the deposition precipitation method. The catalysts prepared by impregnation were active for $\mathrm{CO}$ oxidation at $<25^{\circ} \mathrm{C}$ or $36^{\circ} \mathrm{C}$.

\section{Supported Gold Catalysts for Hydrogen Purification in Fuel Cell Applications}

Alvaro Amieiro-Fonseca, Janet $M$. Fisher and David Thompsett, Johnson Matthey Technology Centre, UK. Low loaded Au catalysts were prepared on a variety of support materials and Au on ceria-zirconia was found to have the highest activity, indicating that the Au-support interaction is crucial. A 2wt\% Au/CeO $-\mathrm{ZrO}_{2}$ catalyst was found to give better performance than commercially available copper catalysts and Pt catalysts in terms of low temperature light off. An $\mathrm{Au} / \mathrm{CeO}_{2}-\mathrm{ZrO}_{2}$ catalyst gave a $20 \% \mathrm{CO}$ conversion at $100^{\circ} \mathrm{C}$ in the water-gas shift (MHSV $\left.=40,000 \mathrm{~cm}^{3} \mathrm{~g}^{-1} \mathrm{~h}^{-1}\right)$.

\section{Preferential Oxidation of CO over Mixed Oxide Supported Au Catalysts}

Abhishek Jain, Xin Zhao, Shane Kjergaard, and Susan M. Stagg-Williams, University of Kansas, USA. The generation of clean hydrogen for PEM fuel cells usually requires selective removal of $\mathrm{CO}$ from hydrogen streams to avoid poisoning of the Pt fuel cell catalysts. The results of this work suggest that Au supported on Fe-Co mixed oxides can be highly active and selective for preferential oxidation of CO (PROX) even at 
temperatures where selectivity is often low. Deactivation studies have shown that the ability of the support to replenish oxygen can be important for long term stability.

\section{Carbon Monoxide Removal from Hydrogen Streams for Fuel Cell Applications}

D L Trimm, CSIRO Petroleum, Australia. Highly dispersed gold on a range of metal oxide supports has been found to promote the preferential oxidation of CO (PROX), with the oxides of $\mathrm{Zr}$, Fe, $\mathrm{Co}, \mathrm{Ni}, \mathrm{Ti}, \mathrm{Ce}$ and $\mathrm{Mn}$ acting as active supports. A clear relationship between catalytic activity and gold particle size has been established, but impurities may affect performance.

\section{Fuel Cell Electrocatalysts: New Approach to the Preparation of Platinum- and Gold- Based Bimetallic Nanoparticles}

Chuan-Jian Zhong, Jin Luo, Mathew M. Maye, Nancy N. Kariuki, Lingyan Wang, Peter N. Njoki, Derrick M. Mott, Yan Lin, I-Im. Stephanie Lim, and Mark J. Schadt, State University of New York at Binghamton, USA. AuPt catalysts have been synthesized using wet chemical methods and capping molecules for molecularly-mediated assembly onto support materials (carbon, silica, etc) and thermal treatment. These catalysts significantly modify the electrocatalytic properties of Pt for both the methanol oxidation reaction at the anode and the oxygen reduction reaction at the cathode of a direct methanol fuel cell.

\section{Oxygen Addition Fully Stabilizes the WGS activity of $\mathrm{Au} / \mathrm{CeO}_{2}$ Catalysts}

Weiling Deng and Maria Flytzani-Stephanopoulos, Tufts University, Medford, USA. The addition of a small quantity of oxygen stabilizes the activity of $\mathrm{Au} / \mathrm{CeO}_{2}$ catalysts in realistic reformate gas compositions, both in long term operation and in cyclic start-stop operation down to room temperature which is accompanied by water condensation. This finding is relevant to mechanistic studies of catalytic activity and may lead to new practical catalyst designs for fuel processing for fuel cells.

\section{A Comparative Study of the Mechanism of the Water-Gas Shift Reaction over Pt and Au catalysts}

J P Breen, R Burch, D Reid, D Tibiletti, A Goguet, FC Meunier,

J Gomez-Lopez, A Ameiro, J Fisher, D Thompsett,

D Thompson and R. Holliday, Queens University Belfast, Johnson Matthey Technology Centre, Reading, UK, and World Gold Council, UK. Au/CeO $-\mathrm{ZrO}_{2}$ and $\mathrm{Pt} / \mathrm{CeO}_{2}$ catalysts were evaluated in a conventional plug-flow microreactor in a reaction mixture designed to mimic that exiting a typical fuel reformer ( $8 \% \mathrm{CO}, 10 \% \mathrm{CO}_{2}, 32.5 \% \mathrm{H}_{2}, 30 \% \mathrm{H}_{2} \mathrm{O}$, balance $\left.\mathrm{He}\right)$. Characterization of the catalysts indicated that they contained gold in an ionic form. The power law rate expressions obtained experimentally indicated significant differences between the two metals. The addition of Au to the support drastically reduces the temperature at which the support can be reduced with either $\mathrm{CO}$ or $\mathrm{H}_{2}$. In the case of $\mathrm{CO}$, reduction even occurred at room temperature.

\section{Oxidation of $\mathrm{CO}$ in $\mathrm{H}_{2}$ by Aqueous Polyoxometalates over Metal Catalysts}

J A Dumesic, G J Rodriguez-Rivera, W B Kim, T Voitl, S T Evans and M A Sanchez-Castillo, University of Wisconsin, Madison, USA. This presentation described a process which the need for use of the WCS during the production of fuel cell grade hydrogen is made unnecessary by direct use of the $\mathrm{CO}$ in the hydrogen as an additional source of energy. Electricity was produced by catalytic oxidation of $\mathrm{CO}$ using gold catalysts at room temperature, using the gold nanotubes in polycarbonate membranes described previously. The observed rates are faster than for conventional processes operating at $500 \mathrm{~K}$ or higher for the conversion of CO with water to produce hydrogen and carbon dioxide through the water-gas shift. The elimination of the need for WGS means that there is no need to transport and vaporize liquid water in the production of energy for portable applications. The process can use CO-containing gas streams from the catalytic reforming of hydrocarbons to produce an aqueous solution of reduced polyoxymetallate compounds that can be used to generate power. The reduced polyoxymetallate can be reoxidized in fuel cells that contain simple carbon anodes.

There were additional papers looking at various catalyst preparation and mechanistic aspects of CO oxidation using gold catalysts on a range of supports and others on propene oxidation catalysts and the water gas shift.

The World Gold Council exhibition stand attracted significant interest and included descriptions of five commercial activities aimed at progressing new applications for gold catalysis. These included a borohydride fuel cell producing useful electricity (QinetiQ), catalyst units from AIST (Japan) used for removing odours from toilets, and descriptions of applications for gold catalysts in gas masks for CO removal (Union Chemical Company, Taiwan), and for oxidizing mercury in the effluent from coal-fired power plants (Tennessee Valley Authority, USA). Project AuTEK (Mintek, South Africa) announced their ability to provide custom-made catalysts in commercially-significant quantities, optimized in collaboration with catalyst end-users (see www.mintek.co.za/autek/CustomMadeCatalysts.htm). 